\title{
A new and high yielding synthesis of unstable pyrroles via a modified Clauson-Kaas reaction
}

\author{
Brendon S. Gourlay, ${ }^{\mathrm{a}}$ Peter P. Molesworth, ${ }^{\mathrm{a}}$ John H. Ryan ${ }^{\mathrm{b}}$ and Jason A. Smith ${ }^{\mathrm{a}, *}$ \\ ${ }^{\text {a }}$ School of Chemistry, University of Tasmania, Private Bag 75, Hobart, Tasmania 7001, Australia \\ ${ }^{\mathrm{b}}$ CSIRO, Division of Molecular and Health Technologies, Bag 10, Clayton South, Victoria 3169, Australia
}

Received 23 August 2005; revised 8 November 2005; accepted 18 November 2005

\begin{abstract}
An investigation of the reaction requirements to effect the Clauson-Kaas pyrrole synthesis led to the formulation of a new procedure that avoids the contact of pyrroles to heat or strongly acidic conditions that cause decomposition of the desired products. The procedure involves mild hydrolysis of 2,5-dimethoxytetrahydrofuran in water to the activated species 2,5-dihydroxytetrahydrofuran that reacts with primary amines in an acetate buffer at room temperature to give $N$-substituted pyrroles in high yield. In the case of chiral amines, pyrrole formation proceeds with no detectable epimerisation. Acid- or heat-sensitive pyrroles are also obtained in high yield and purity.
\end{abstract}

(c) 2005 Elsevier Ltd. All rights reserved.

Recently we reported the synthesis of 5-alkyl substituted indolizidine alkaloids such as indolizidine 209D from the ring opening of $\gamma$-lactones with pyrrole to give $\gamma$ pyrrolic ester derivatives 2 (Scheme 1 ). ${ }^{1}$ This approach is somewhat limited by the difficulty of the ring opening reaction with substituted lactones and an asymmetric synthesis was not viable due to the prohibitive cost and lack of availability of enantiopure lactones.

To overcome these limitations, we turned to the Clauson-Kaas pyrrole synthesis that utilises the condensation

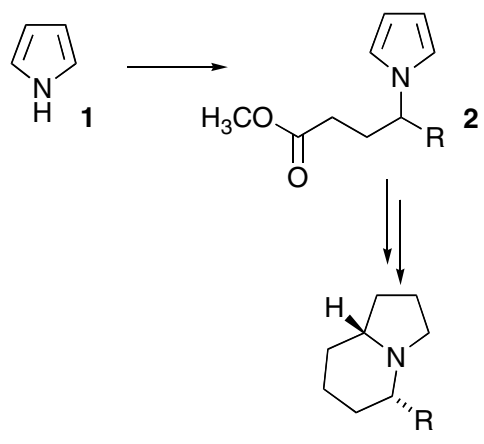

$\mathrm{R}=n-\mathrm{C}_{6} \mathrm{H}_{13}( \pm)$-indolizidine $209 \mathrm{D}$

Scheme 1. Synthesis of indolizidine alkaloids from $\gamma$-pyrrolic esters.

\footnotetext{
*Corresponding author. Tel.: +61 36226 2182; fax: +61 36226

2858; e-mail: Jason.Smith@utas.edu.au
}

of an amine and 2,5-dimethoxytetrahydrofuran (3) for the synthesis of our required $N$-substituted pyrroles (Scheme 2). ${ }^{2}$ The use of chiral $\alpha$-amino esters in the Clauson-Kaas reaction would yield $\alpha$-pyrrolic esters that could undergo a two carbon homologation ${ }^{3}$ to give the desired $\gamma$-pyrrolic esters 2 required for an asymmetric synthesis of the target molecules.

The methods reported for the Clauson-Kaas reaction work well for stable substrates and products; however, extension of the available methods to acid- or heat-sensitive substrates or products is rare and in such cases side products or low yields of the desired products have been reported. For instance, condensations of $\alpha$-amino acids and esters with 2,5-dimethoxytetrahydrofuran usually require heating to reflux in acetic acid or other high boiling solvent and give inconsistent yields and product of poor quality due to pyrrole decomposition processes. ${ }^{4}$ Attempts to overcome these difficulties include Jefford's use of a two phase system, which removes the acid-sensitive pyrrole from the acidic aqueous layer. ${ }^{5}$ This approach gave improved yields (59-81\%) with higher ee's; however, in the case of more sensitive

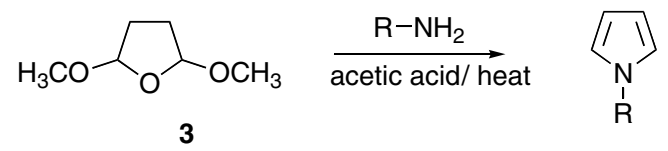

Scheme 2. Clauson-Kaas pyrrole synthesis. 
products the yields were not consistently high due to decomposition by contact with acid or heat or both. These methods are not sufficiently robust for the preparation of the types of compounds that we require as starting points for an asymmetric synthesis. With this as a major stumbling block in our synthetic path we embarked on an investigation of the requirements to effect the Clauson-Kaas reaction. While acid or heat are required to promote hydrolysis of 2,5-dimethoxytetrahydrofuran to the more reactive dialdehyde, which exists as the dihydroxy furan $\mathbf{4}$ under the aqueous conditions, we reasoned that these conditions may not be necessary for the condensation of $\mathbf{4}$ with the amine to yield the pyrrole ${ }^{6}$ (i.e., Paal-Knorr reaction). Therefore, we proposed to decouple these two processes for our current synthesis of $N$-substituted pyrroles such that exposure of the pyrroles to heat or strong acid could be avoided altogether.

The hydrolysis of $\mathbf{3}$ is typically performed using mineral acids such as hydrochloric or sulfuric acid. ${ }^{7}$ As we wished to avoid the use of strong acids, we investigated the use of aqueous acetic acid. The use of acetic acid would also mean that after hydrolysis sodium acetate could be added to generate a buffer of $\sim \mathrm{pH} 5$ for the pyrrole formation. ${ }^{1} \mathrm{H}$ NMR studies of the hydrolysis of $\mathbf{3}$ were undertaken and showed that heating a solution of the furan in $\mathrm{D}_{2} \mathrm{O}$ with 1 equiv of acetic acid resulted in the complete hydrolysis in $1 \mathrm{~h}$ and clearly demonstrated that strongly acidic conditions were not required. Surprisingly, it was also observed that simple heating in $\mathrm{D}_{2} \mathrm{O}$ without acid resulted in the hydrolysis of the acetal within $2 \mathrm{~h}$ indicating that acid was not necessary for the hydrolysis step (Scheme 3 ). In the latter case, addition of ammonia to the NMR tube resulted in only a trace of pyrrole. In contrast, when ammonium chloride and sodium acetate were added to the solution of $\mathbf{4}$ in $\mathrm{D}_{2} \mathrm{O}$, formation of pyrrole was observed. Therefore, while acid is not required for the activation or hydrolysis of 2,5-dimethoxytetrahydrofuran, a solution of $\mathrm{pH}<7$ is required to promote formation of the pyrrole. These observations were then considered in designing the synthetic method.

The synthetic method was then carried out by heating 2,5-dimethoxytetrahydrofuran in water at reflux for $2 \mathrm{~h}$ under nitrogen to form dihydroxytetrahydrofuran 4. The solution was cooled to room temperature, dichloromethane was added followed by the amine and 1 equiv of both acetic acid and sodium acetate to form a buffer of $\sim \mathrm{pH}$ 5. After stirring at room temperature overnight, a high yield of the pyrrole was observed. Both free amines and hydrochloride salts can be used with this procedure; however, for hydrochloride salts of amines no acetic acid was required and 2 equiv of sodium acetate were added to maintain a buffer of $\sim \mathrm{pH} 5$. The

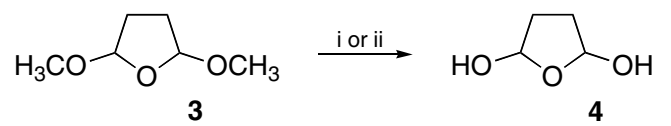

Scheme 3. Reagents and conditions: (i) $\mathrm{D}_{2} \mathrm{O}, 1$ equiv $\mathrm{AcOH}$, reflux $1 \mathrm{~h}$; (ii) $\mathrm{D}_{2} \mathrm{O}$, reflux $2 \mathrm{~h}$. crude products were usually obtained as colourless oils, which contrasted with the dark brown to black tarry material (indicative of decomposition of the pyrrole nucleus) often obtained by other literature methods. The products could then be purified simply by passing through a short plug of silica to yield the desired compound in a pure state. We have applied this procedure to both achiral and chiral substrates including amines as the free base or the hydrochloride salt. The results of these experiments are shown in Table 1.

In general, the yields of isolated products were excellent and consistently higher than those cited most recently (59-81\% for amino esters). ${ }^{5}$ The importance of generating 4 as an intermediate is highlighted by the fact that the yield of the product in entry 1 was only $\sim 10 \%$ when the initial refluxing of $\mathbf{3}$ in water was omitted. The $\mathrm{pH}$ of the reaction was also shown to be important as a $31 \%$ yield of pyrrole product was obtained from $R$-(-)-phenylethylamine when the amine was added to 4 in the absence of acetate buffer compared to a $91 \%$ yield obtained under buffered reaction conditions (entry 4). Scale up of the procedure was readily achieved with the product from L-alanine methyl ester being synthesised on a multigram scale without decline in yield or resulting difficulty in isolation of the pure product. The mild reaction conditions result in no detectable racemisation of the stereogenic centre of any of the chiral substrates under the conditions with ee's of all substrates being $>99 \%$ as determined by chiral gas chromatography. Previously, most attempts to increase the product yield led to compromised ee's due to epimerisation under the reaction conditions that were employed. For example, the recent report of the synthesis of pyrroles from the methyl esters of alanine and norvaline gave high ee's; however, the yields were relatively moderate $(\sim 70 \%) .{ }^{8}$ In addition, the mild reaction conditions are highlighted by the fact that sensitive products, which are prone to elimination reactions such as the pyrroles obtained from serine, $\beta$-alanine and $( \pm)$-methyl 4-amino-3-hydroxybutyrate were isolated in high yield. ${ }^{9}$ In our hands, the latter product could not be isolated under the conventional Clauson-Kaas conditions due to rapid decomposition and formation of black tarry material. Similarly, the serine derivative (entry 3 ) is prone to dehydration under acidic conditions and was reported in only a $19 \%$ yield employing standard conditions. ${ }^{10}$

In summary, we have shown that a one-pot two-step method involving hydrolysis of 2,5-dimethoxytetrahydrofuran followed by the addition of the amine in a buffered solution gives pyrroles cleanly, in excellent and reproducible yield. The method has allowed the preparation of acid- or heat-sensitive pyrroles for the first time in high yield, high ee and high purity. Couple these points with the fact that the method can readily be carried out on a multigram scale with easy purification and the procedure has the potential to be a widely adopted method for the synthesis of pyrrole derivatives.

Representative procedure: 2,5-Dimethoxytetrahydrofuran $(0.200 \mathrm{~mL}, 1.544 \mathrm{mmol})$ was added to a stirred solution of water $(2.0 \mathrm{~mL})$ and the solution was refluxed 
Table 1. Yields and ee's of pyrroles from the modified Clauson-Kaas reaction

\begin{tabular}{|c|c|c|c|}
\hline Entry & Amine & Product & Yield $/ \%{ }^{\mathrm{a}}(\mathrm{ee} / \%)^{\mathrm{b}}$ \\
\hline 1 & L-Alanine methyl ester hydrochloride & & $93(99)$ \\
\hline 2 & D-Norvaline methyl ester hydrochloride & & $94(99)$ \\
\hline 3 & L-Serine methyl ester hydrochloride & & $89(99)$ \\
\hline 4 & $R$-(-)-Phenylethylamine & & $91(99)$ \\
\hline 5 & $\gamma$-Aminobutyric acid methyl ester hydrochloride & & 91 \\
\hline 6 & $\beta$-Alanine methyl ester hydrochloride & & 90 \\
\hline 7 & $( \pm)$-4-Amino-3-hydroxybutyric acid methyl ester hydrochloride & & 93 \\
\hline
\end{tabular}

\footnotetext{
${ }^{\mathrm{a}}$ Yields quoted are isolated yields.

b ee's Determined by chiral GC on an Agilent Technologies Cyclosil B capillary (30 m, $0.25 \mathrm{~mm}, 0.25 \mu \mathrm{m})$ featuring a 30\% heptakis $(2,3$-di- $O$-methyl6-O-tert-butyldimethylsilyl)- $\beta$-cyclodextrin in DB-1701 stationary phase.
}

for $2 \mathrm{~h}$ under nitrogen. The mixture was allowed to cool to room temperature, before the addition of dichloromethane $(3.0 \mathrm{~mL})$, sodium acetate $(0.304 \mathrm{~g}, 3.705 \mathrm{mmol})$ and L-alanine methyl ester hydrochloride $(0.165 \mathrm{~g}$, $1.852 \mathrm{mmol})$. The reaction mixture was then stirred vigorously for $15 \mathrm{~h}$ with exclusion from light. The reaction mixture was made alkaline with $2 \mathrm{M}$ sodium carbonate $(5 \mathrm{~mL})$, and the pyrrole extracted with dichloromethane $(3 \times 5 \mathrm{~mL})$. The organic extracts were dried over magnesium sulfate and filtered through a plug of silica gel with ethyl acetate/hexanes (1:4) and the solution concentrated to yield the pyrrole derivative in $93 \%$ yield as a colourless oil.

\section{Acknowledgements}

The authors would like to thank The University of Tasmania for research funding through the Institutional Research Grants scheme and to ACROS Organics for the provision of $\gamma$-amino acids. B.S.G. is grateful for a CSIRO postgraduate scholarship. P.M.M. is grateful to the University of Tasmania and the University of Warwick for a travel award. The authors would also like to thank Mr. Douglas S. McLean for assistance with chiral gas chromatography.

\section{Supplementary data}

${ }^{1} \mathrm{H}$ and ${ }^{13} \mathrm{C}$ NMR spectra are available as Supplementary data. Supplementary data associated with this article can be found, in the online version, at doi:10.1016/ j.tetlet.2005.11.104.

\section{References and notes}

1. Amos, R. I. J.; Gourlay, B. S.; Molesworth, P. M.; Smith, J. A.; Sprod, O. R. Tetrahedron 2005, 61, 8226-8230.

2. Clauson-Kaas, N.; Limborg, F.; Kakstorp, J. Acta Chem. Scand. 1948, 2, 109-115.

3. Banwell, M. G.; Beck, D. A. S.; Smith, J. A. Org. Biomol. Chem. 2004, 2, 157-159.

4. Greiner, P. Heterocyles 1991, 32, 1499-1504; Tembo, O. N.; Dallamagne, P.; Rault, S.; Robba, M. Heterocyles 1993, 36, 2129-2137; Artico, M.; Corelli, F.; Massa, S.; Stefancich, G. Synthesis 1983, 11, 93.

5. Jefford, C. W.; de Villedon de Naide, F.; Sienkiewicz, K. Tetrahedron: Asymmetry 1996, 7, 1069-1076.

6. A similar approach was reported for the synthesis of 3,4-dialkoxypyrroles from the corresponding 2,3,4,5-tetraalkoxyfuran, see: Merz, A.; Meyer, T. Synthesis 1999, 94-99.

7. Fakstorp, J.; Raleigh, D.; Schmiepp, L. E. J. Am. Chem. Soc. 1950, 72, 869-874; Mueller, R.; Yang, J.; Duan, C.; Pop, E.; Zhang, L. H.; Huang, T.-B.; Denisenko, A.; Denisko, O. V.; Oniciu, D. C.; Bisgaier, C. L.; Pape, M. E.; Freiman, C. D.; Goetz, B.; Cramer, C. T.; Hopson, K. L.; Dasseux, J.-L. H. J. Med. Chem. 2004, 47, 5183-5197.

8. Settambolo, R.; Guazzelli, G.; Mengali, L.; Mandoli, A.; Lazzaroni, R. Tetrahedron: Asymmetry 2003, 14, 2491-2493.

9. The pyrrole derivative from $( \pm)$-methyl 4-amino-3hydroxybutyrate is a new compound and its spectral data is given below: [Found $\mathrm{M}^{+}, 183.0889 \mathrm{C}_{9} \mathrm{H}_{13} \mathrm{NO}_{3}$ requires 183.0895]; $v_{\max }\left(\mathrm{cm}^{-1}\right) 3474,1732 ;{ }^{1} \mathrm{H}$ NMR $(300 \mathrm{MHz}) \delta$ : $2.44(\mathrm{~d}, J=4.5 \mathrm{~Hz}, 2 \mathrm{H}), 2.72(\mathrm{br} \mathrm{s}, 1 \mathrm{H}), 3.71(\mathrm{~s}, 3 \mathrm{H}), 3.95$ $(\mathrm{m}, 2 \mathrm{H}), 4.28(\mathrm{~m}, 1 \mathrm{H}), 6.16(\mathrm{app} \mathrm{t}, 2 \mathrm{H}), 6.69($ app t, $2 \mathrm{H})$; ${ }^{13} \mathrm{C}$ NMR $\delta: 38.4,52.2,54.6,68.4,108.9,121.6,172.7 ; \mathrm{m} / \mathrm{z}$ (EI) $183(90 \%), 165(10), 152(10), 134$ (25), 80 (100).

10. Kashima, C.; Maruyama, T.; Harada, K.; Hibi, S.; Omote, Y. J. Chem. Res. (S) 1988, 62-63. 